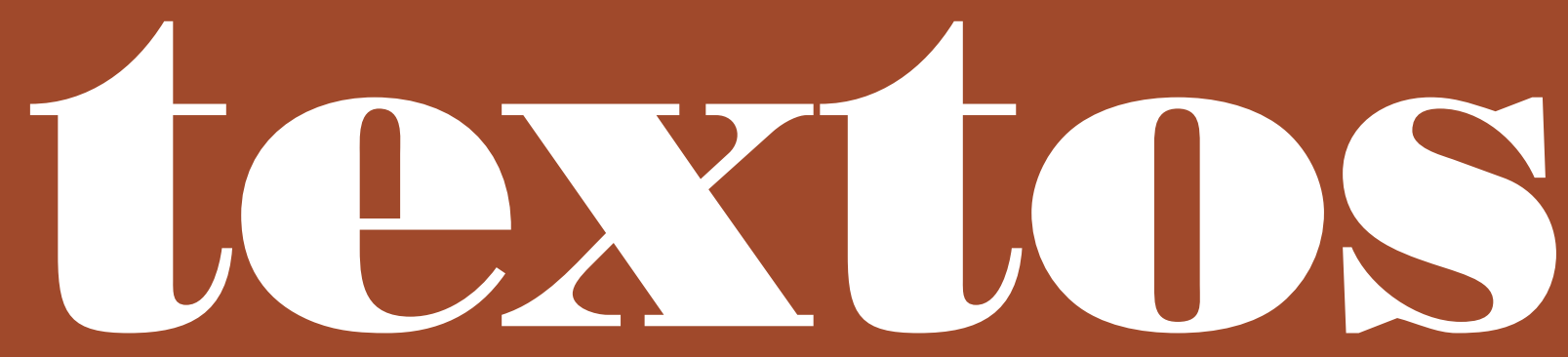





\title{
Jacó Guinsburg
}

\section{e a Editora Perspectiva}

\author{
Roberto Romano
}

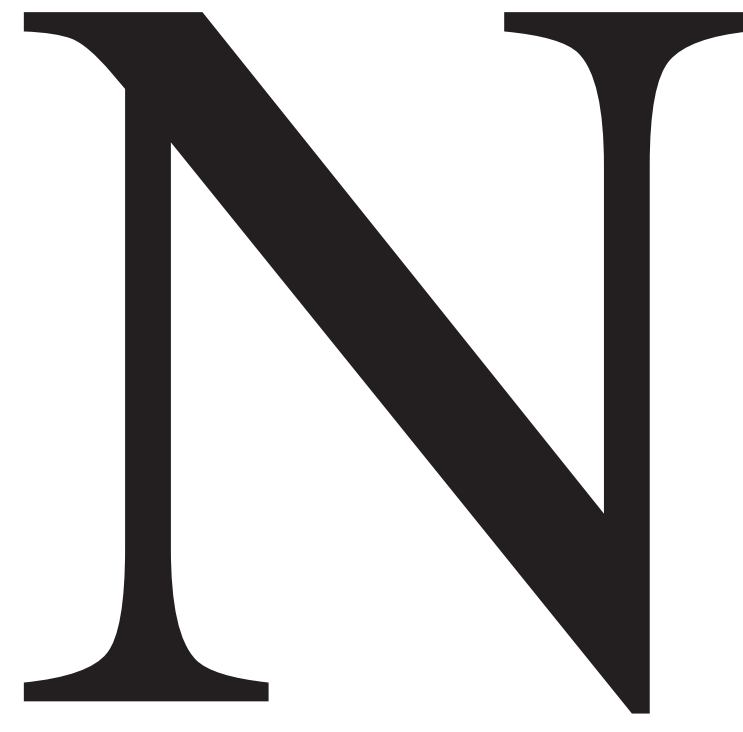

o Pantagruel, Rabelais narra o encontro do herói com Panurgo, "a quem ele amou toda a vida”. Ao enxergar o amigo futuro, de miserável aparência, Pantagruel lhe pergunta numa torrente frásica: "Qui estes-vous? d'où venez-vous? Où allez-vous? Que querez-vous \& quel est vostre nom?". A resposta vem caudalosa, como se o estranho habitasse Babel. Ele fala, primeiramente, em alemão. Depois move uma fieira de línguas antigas e modernas, do árabe ao italiano, inglês, basco, espanhol, etc. Em dado momento os companheiros perguntam: "Parlez-vous Christian, mon amy?". Nova catadupa de respostas reúne o hebraico, o dinamarquês e outras falas. Finalmente surgem na sua boca o francês e a confissão: nascera na França, mas vinha da Turquia... "Falar cristão", em Rabelais, era atingir o inexistente idioma culto universal, que integraria o projeto otimista de um novo elo entre os homens (cf. Hampton, 2009, p. 31).

ROBERTO ROMANO é professor de Ética e Filosofia na Unicamp e autor de, entre outros, Razão de Estado e de Outros Estados (Perspectiva). 
A situação do mundo, quando Rabelais escreve, é a confusão dos saberes e direções espaciais, com a redescoberta do grego, judaico, arábico, escrínios onde se alojam Platão, Aristóteles, Hipócrates, Sêneca, Cícero, Avicena, Averrois e tantos mestres do saber. Na política, os estados se consolidam, conquistam terras no Ocidente e no Oriente. Profusão de idiomas à espera de uso técnico e diplomático, tesouros a serem explorados pelos príncipes e comerciantes, militares, missionários.

Nasce o editor. Sua tarefa é dinamizar o filtro por onde passam milênios de sapiência e loucura, filosofia e sátira, história e política, matemática e astronomia, ética e poética, tratados bélicos e médicos, geografia e diários de viagem, ocultismo e teologia. No moinho das prensas, sob liderança de intelectuais notáveis, o editor é mola mestra da cultura renascentista. Indica Jean Guillemain que o editor aparece no século XVI como ente polifacetado. Ele imprime, encaderna e vende os volumes sob sua guarda. Trata-se de um afazer de comércio à procura de capitais, mas também intelectual (unido aos autores e tradutores) e político (elos com autoridades civis e religiosas). Comércio supõe concorrência e, para vencer adversários pouco éticos, editores se reúnem em companhias, com frequência para temporadas curtas e vendas definidas (por exemplo, para viabilizar a vendagem de certo livro). Para editar, eles trabalham com especialistas nos textos gregos e latinos, filtram borrões nos textos causados pelos copistas medievais.

É assim a tarefa de Aldo Manucio, em Veneza, ao imprimir gregos e latinos trazidos de Constantinopla: ele reúne helenistas como Lascaris, Musurus, Erasmo, Bembo. Em Paris, Josse Bade coordena o trabalho liderado por Lefèvre d'Etaples, Guillaume Budé, Beatus Rhenanus, Erasmo. Em suas oficinas e ao redor delas a língua francesa recebe sua codificação. Surgem editores e companhias em cidades universitárias e urbes comerciais. Veneza, Florença, Lyon, Anvers, Rouen, Frankfurt, Paris, Colônia, Bâle, Leipzig se transformam em centros de irradiação cultural sob a batuta dos editores. Com a Reforma, a demanda pela Bíblia impressa, a busca de tratados, panfle- tos contrários à Sé romana trazem alento aos editores e seus liderados. No lado católico se expande a procura de livros e panfletos além da Bíblia editada sob vigilância dos censores eclesiásticos. Livros de piedade aparecem aos borbotões para vencer a heresia protestante $\mathrm{e}$ outras heresias, como o ateísmo materialista que dá o ar da graça na esteira de Lucrécio․ No século XVIII, na França, 150 cidades possuem casas impressoras. Paris é o núcleo, e os editores da província se limitam geralmente à reimpressão (legal ou clandestina).

Separa-se pouco a pouco o livreiro do impressor. O editor, como é conhecido hoje, se afirma no século XIX. A sua figura exemplar é Charles Joseph Panckoucke. E aparece o editor de ciências, cuja efígie é reconhecível em Denis Diderot, na Encyclopédie (Michèle Sacquin, s/d). No século XX a cultura passa ao democratismo, o número dos alfabetizados aumenta, a imprensa penetra os ambientes, os editores entram numa era estratégica na qual seu poder se alicerça na aliança com especialistas na Europa e nos EUA sobretudo. As editoras universitárias ampliam textos e revistas, garantem influências para grupos e lobbies de acadêmicos. Estes últimos asseguram para o livro lugar relevante nos meios audiovisuais, do cinema à $\mathrm{TV}$, desta ao rádio. Editores recebem e fazem a corte aos mestres da hora, o que garante espaços e resenhas em revistas de grande público ou aos setores restritos de universitários especializados $^{2}$. As ideias se repartem em todos os matizes ideológicos, religiosos, científicos. A editora se afirma como artífice de soberanias

1 Tais informações são extraídas do excelente texto, publicado pela Biblioteca Nacional de Paris, sobre a história do livro, escrito por vários autores. O Renascimento e a Reforma foram tratados por Jean Guillemain (s/d).

2 Uma análise hilariante e, no entanto, exata, do reino editorial francês é feita por H. Hamon e P. Rotman (1981). Os autores traçam a crônica dos intelectuais franceses, divididos entre as louvaminhas aos editores e a presença na mídia, sobretudo na TV. Daía geração dos acadêmicos "mediáticos", que fazem enorme sucesso por alguns dias. Depois, são trocados por outros e outros. Muitos nomes, exaltados em teses e dissertações brasileiras, mostram face pouco lisonjeira nos tratos com editores e jornalistas. O trabalho de Hamon e Rotman foi atualizado por Elisabeth Lévy (2002), em virulenta exposição dos intelectuais franceses e sua batalha na mídia. 
políticas, artísticas. As verbas e o verbo se conjugam ao impor o que Antonio Gramsci batiza como pensamento hegemônico ${ }^{3}$. Bolsas de pesquisa e de estudos brotam dos lobbies que se digladiam ao redor dos editores.

O absolutismo europeu, para garantir a raison d'état que o sustenta, favorecera os livros impressos e o jornalismo panfletário. Com a proteção veio a censura civil, antes quase um monopólio da Igreja. Os governos apoiam a edição e a controlam. Na faina, reúnem intelectuais e gazeteiros ao redor da corte e contra ela. $\mathrm{Na}$ Inglaterra, a imprensa, a partir de Henrique VIII e de Isabel, é controlada nos palácios. Com a Revolução Puritana, pelo menos no início, ocorre a defesa das letras e do jornalismo. John Milton imortaliza o anseio de liberdade. No continente, Richelieu e seus êmulos financiam publicações científicas e humanísticas, no mesmo átimo em que sustentam propagandistas da corte (Catteeuw, 2013; Thuau, 2000). As bases do Estado moderno, com o absolutismo, são ideadas nas oficinas de impressão, sob a liderança de editores opostos ou empenhados na política oficial.

O Brasil vive o período absolutista sob o guante português. Se na metrópole a impressão

3 Conhecida desde o Renascimento, a técnica de promoção e de autopromoção dos lobbies (Jardine, 2015) foi muito usada no século XVIII. Diderot e Rousseau a empregaram profusamente. $O$ último anunciou durante anos, antes da publicação, a sua Nova Heloisa, num efeito de propaganda eficaz. Segundo Palissot, inimigo certeiro dos enciclopedistas, nem mesmo os muçulmanos falariam com tanto entusiasmo do Corão, como Diderot e seus amigos proclamavam o seu trabalho. Como fazer um livro conhecido no século XX? "É preciso que uma obra desperte o interesse antes de sua saída. Se os rumores são muito imperceptíveis, o editor mobiliza os jornalistas amigos. Ele paga uma saraivada de anúncios lisonjeiros. Será 'o acontecimento da nova estação', 'a polêmica do ano', ou ainda 'um livro muito esperado'. Nesse estágio, a publicidade visa menos o público do que os propagadores paroquiais para quem não ter recebido, lido ou pelo menos visto o livro antes de sua comercialização seria como parecer, à beira do Sena, um camponês do Danúbio. Os verdadeiros privilegiados são as cinco ou seis assinaturas importantes: o editor Ihes envia, amigavelmente e de modo confidencial, as provas... gentileza interessada, além dos artigos que abrem a porteira ao público, ela visa obter páginas no Nouvel Observateur, Le Point, Paris-Match, L'Express" (Hamon \& Rotman, 1981, p. 131). Os autores se esqueceram, nesse ponto, do Le Monde e outros veículos estratégicos. O procedimento na Inglaterra, Alemanha, Itália ou EUA é absolutamente igual. e a editoria de livros são medíocres ${ }^{4}$, na colônia é proibido (sobretudo após a Revolução Puritana inglesa) editar e comercializar livros. A polícia aterroriza leitores. Não supreende que os rebeldes, em especial os de Minas, leiam de modo sigiloso escritos editados na França, na Inglaterra, na então recente federação norte-americana (Frieiro, 1946). Mas foram lidos e comentados textos clássicos e novidades, mesmo em forma abreviada, como no caso da Encyclopédie Méthodique, um reordenamento da Encyclopédie diderotiana, além de Voltaire, Locke e outros ${ }^{5}$. Consumidores de livros existem, mas o jugo lusitano impede aqui a livre produção editorial. E assim fomos até o século XIX, antes da corte e da imprensa régia, a publicação da Gazeta do Rio de Janeiro (1808). Desde então, surgem editoras em todo o território.

Dado o prestígio das Luzes, das insurreições coloniais, sob o signo revolucionário de 1789 , a cultura da França é um modelo para os nossos escritores. Dessa fama souberam aproveitar as editoras Garnier e Laemmert, ambas fechadas no começo do século XX (Rocha, 2009). E vieram Monteiro Lobato, o Departamento de Imprensa e Propaganda (DIP) e o controle das edições na ditadura, o apoio da fina flor intelectual ao regime de força. Logo se seguiu a lista de editores encabeçada por José Olympio, Joaquin Inácio da Fonseca Saraiva, Ênio da Silveira, Caio Prado Junior, Jean-Paul Monteil. Com este último, encerro a lista e passo ao objeto do presente artigo, Jacó Guinsburg e a Perspectiva.

Na Editora Difusão Europeia do Livro, Guinsburg trabalha com um editor que une a cultura à opção política progressista. Essa marca o jovem Jacó a tem, mas ali cresce o círculo de suas relações intelectuais. Então, traduz textos de filósofos nucleares da vida moderna, como Descartes e Sartre. Recebida uma bolsa de estudos francesa, conhece a vanguarda do

\footnotetext{
4 No século XVI, apenas dois impressores operam em Lisboa, depois o francês German Gaillar é o único impressor em Portugal. No fim do mesmo século, aumenta a produção de livros, mas em escala muito inferior à efetivada nos demais países europeus (cf. Jean Guillemain, s/d).

5 Ver o excelente trabalho de Christianni Cardoso Morais
} (2002). 
pensamento filosófico e teatral. A perene crise brasileira tolda os ares culturais, gera desentendimentos em toda parte. Jacó desata os laços que o unem a Monteil. Daí, o desemprego e o trabalho de tradução na Editora Cultrix, com um pensador que o inspira até hoje. Eu diria, persegue, dada a tenacidade do seu trato com Diderot.

Carlos Ortiz marca a trajetória de Guinsburg. Escritor poliglota, tinha no apuro de estilo o seu grande trunfo. Após deixar o sacerdócio católico ele militou na área cultural, sobretudo no cinema. E auxilia os primeiros passos do jovem editor na Rampa, casa de publicação de vida breve. Figura luminar nas sendas de Jacó (e da editora) é Anatol Rosenfeld. Trata-se de uma figura que ainda não recebeu o tributo merecido na universidade brasileira. O seminário de filosofia por ele ministrado, a convite dos Guinsburg, Jacó e Gita, ajudou a introduzir na república uspiana os alemães, entre eles os da chamada Escola de Frankfurt. Com Rosenfeld, os ouvintes esmiúçam os lados frágeis do existencialismo, percebem o sutil veneno trazido por Heidegger. Alheio à especialização burocrática do mundo universitário, Anatol uniu estética e epistemologia, com resultados surpreendentes em análises literárias, dos românticos a Brecht. O interesse de Guinsburg pelo teatro não se explica pelo relacionamento com Rosenfeld, mas foi por ele impulsionado. Ao escrever sobre teatro para o jornal $O$ Estado de S. Paulo, Jacó mostra exemplar acuidade e talento analítico, o que o leva ao professorado na USP.

Ao criar a Perspectiva, Guinsburg retoma o impulso sumariamente descrito acima, do Renascimento aos nossos dias. A editora nasce em 1965, um ano após o infausto golpe de Estado que gerou execrável caça às bruxas (e aos livros progressistas). Em autos da fé ridículos e trágicos, livros de capa vermelha foram apreendidos e danificados pela polícia repressiva. Bibliotecas foram invadidas, coisas de envergonhar um país civilizado. As tolices censórias ocasionaram a sátira de Stanislaw Ponte Preta sobre o Febeapá. A onda incontida das delações torna o ambiente social e político irrespirável. A Perspectiva, no rumo oposto ao da escuridão imperante, sem deixar o interesse pela cultura judaica, escolhe a mais ampla universalização do saber. Ela não se prende a compromissos ideológicos ou partidários, mas aposta, como as Luzes e o Renascimento, na cultura que lança raízes na história planetária. Guinsburg retoma a tradição renascentista e das Luzes, sintetizadas acima.

Essa marca segue a editora e o seu mentor até hoje. As suas coleções ligam o particular e o geral, ao que conduz ao universo cultural. Os próprios nomes indicam o amplo diálogo, ao estilo humanista: Debates, Signos, Estudos. Chego à parceria de trabalho entre Jacó e a professora Gita, sua esposa. Erudita e refinada leitora, ela domina a matemática e a lógica, ciências e humanidades. A coleção Big Bang testemunha o quanto Gita é essencial na editora. Mas todos os títulos publicados têm a sua parte de escolha, sugestão, labor. Como poucos casais na república das letras, Gita e Jacó podem ser representados numa hipóstase de personalidades distintas e autônomas agindo em harmonia. O resultado é um contributo único à nossa vida espiritual.

Como os renascentistas e modernos, os Guinsburg reúnem ao redor da editora uma grande quantidade de intelectuais que nela publicam seus pensamentos e indicam livros de interesse mundial para serem impressos. Celso Lafer, Haroldo de Campos, Trajano Vieira, João Roberto Faria, João Alexandre Barbosa e tantos mais formam a constelação das mentes que brilham no firmamento do qual Guinsburg é o Atlas. Do labor coletivo coordenado na Brigadeiro Luiz Antonio, surgiram edições dos clássicos antropológicos, literários, filosóficos, poéticos, teatrais. Entre os picos na edição, no meu modesto entendimento, lembro os belíssimos Mimesis, de Erich Auerbach, Obra Aberta, de Umberto Eco, Homo Ludens, de Johan Huizinga, as Obras, de Diderot, Descartes, Platão e outros esteios do intelecto e da racionalidade. No campo judaico, o lancinante escrito de Saul Friedländer, A Alemanha Nazista e os Judeus, as Obras Completas, de Spinoza, a coletânea Do Estudo e da Oração, coordenada por Jacó Guinsburg, A Orquestra do Reich, de Misha Aster, Jesus e Israel, de Jules Isaac. Entre tantos outros autores, temos Boulez, Gropius, Anatol Rosenfeld, Geershom Scholem, Elias Canetti, Leon Poliakov, Octavio Paz, Walter Benjamin, 
Hanna Arendt, Martin Buber, Boris Schnaiderman, Jacques Derrida, Gustavo Hocke, Mircea Eliade, Jean Starobinski. A enumeração é difícil, tal a diversidade e a riqueza trazida às coleções da Perspectiva por nomes relevantes do cosmo espiritual moderno e contemporâneo.

Após o Renascimento e o advento da imprensa, temos a revolução nas comunicações, com o rádio e a TV. Na era da internet, a cultura digital atinge seu ápice. Entre as técnicas do livro no Renascimento e a cultura digital que hoje se firma, mudanças substanciais ocorreram. Muitas editoras seguem os novos processos com textos assumidos e manipulados simultaneamente por leitores que se tornam coautores. Logo chegaremos ao exigido por Pascal: os livros serão "nossos", não "meus". O texto, o hipertexto, o intertexto, anseio dos que idealizaram o nosso mundo cultural, surgem como promessa encantadora. Mas o nosso tempo ainda respira o ar do livro na política, religião, academias. Os libelos que deram início à ordem moderna, usados por amigos e inimigos do Estado absolutista, foram trocados pelo Facebook, antes do samizdat e dos mimeógrafos movidos contra regimes tirânicos. Entre certos tipos de escritura e os tratados, os decretos, os livros santos, há uma distância de forma, que de minuto a minuto se dirige para a coincidência. E, não obstante, dogmas obscuros, intolerantes, são veiculados na internet e aterrorizam, arrefecem o pensamento e a autonomia humana. Todas as grandes editoras do mundo sofrem crises econômicas, espirituais, políticas. O fechamento de casas como as Presses Universitaires de France, os apuros das editoras universitárias europeias e norte-americanas, o sucesso de firmas pouco ortodoxas em termos éticos, que se aproveitam dos textos impressos e os veiculam na internet - não raro de modo pirata -, tudo mostra não só o esgotamento de modelos editoriais, mas profunda indigência espiritual. A pletora de informações não compensa a miséria do pensamento ${ }^{6}$. Breve as pessoas precisarão perguntar aos faladores de todas as línguas, os gárrulos propagandistas de ódio e cizânia das "redes sociais": "Parlez-vous Christian"? Enquanto a resposta for negativa, estaremos sob o domínio do pedantismo, agora eletrônico.

A Editora Perspectiva, que abriu as portas brasileiras para a cultura contemporânea, sem chauvinismo ou parti pris sectário, faz 50 anos e chega à maturidade em tempo do "ainda não". Ela já é um sucesso no campo do livro e ainda não impera, na ordem do pensamento, na literatura eletrônica. No parto da nova Renascença, temos a reiterada moléstia do pedantismo, nas Wikipédias e quejandos. A democratização da cultura segue o ritmo do mercado e da tecnologia. A inflação de informações não processadas com apuro crítico enche as telas dos computadores e trava a mente de quem os usa. Como ilha de saber, a Perspectiva ensina a pensar palavras e conceitos. Talvez seja este o contributo maior da editora: ajudar os futuros leitores/autores a filtrar ideias, pesá-las, para salvar futuras gerações do pedantismo e certezas dogmáticas. Feliz aniversário para todos nós, enriquecidos com a luta pelo saber e gosto, no trabalho editorial. Obrigado Jacó. Como um outro judeu de estatura universal, você pode dizer: "Bonum certamen certavi, cursum consummavi, fidem servavi"!?.

6 A situação é bem mais grave do que seu aspecto financeiro ou político. Trata-se de um novo início cultural em termos planetários. O livro impresso trouxe o pedantismo e a especulação comercial. Mas de muitos dejetos surgiram frutos raros e excelentes, como Montaigne, Rabelais, Erasmo e outros. Talvez em alguns séculos tenhamos os frutos excelentes da internet. Por enquanto, salvo sites relevantes (cito o Projeto Perseus, a Bibliothèque National de France com a Gallica, e outros), o público afoga no mar das informações superficiais, sem apuro crítico ou gosto. As tentativas mais fortes para entender a crise editorial se concentram no lado econômico, sem descer à grave ruptura de paradigma noético trazida pela internet (cf. J. Aguiar, 2015, p. D4).

7 "Combati o bom combate, acabei a carreira, guardei a fé" (Paulo ou Saulo de Tarso, 2 Timóteo, 4). 


\section{BIBLIOGRAFIA}

AGUIAR, J. "Crise Afeta Ânimo do Mercado Editorial", in Valor Econômico, 4, 5 e 6 de julho, 2015, p. D4.

CATTEEUW, Laurie. Censures et Raisons d'État. Paris, Albin Michel, 2013.

FRIEIRO, Eduardo. O Diabo na Livraria do Cônego. Belo Horizonte, Cultura Brasileira, 1946.

GUILLEMAIN, Jean. "Renaissance et Reforme", in Histoire du Livre. Paris, BnF, s/d. Disponível em: http://classes.bnf.fr/livre/arret/histoire-du-livre/renaissance/02.htm. Consultado em 4/5/2015.

HAMON, H.; ROTMAN, P. Les Intellocrates, Expédition en Haute Intelligence. Paris, Complexe, 1981.

HAMPTON, Thimothy. Fictions of Embassy, Literature and Diplomacy in Early Europe. Ithaca/ London, Cornell University Press, 2009.

JARDINE, L. Erasmus, Man of Letters, the Construction of Charisma in Print. New Jersey, Princeton University Press, 2015.

LÉVY, Elisabeth. Les Maîtres Censeurs. Paris, Le Livre de Poche, 2002.

MORAIS, Christianni Cardoso. Para Aumento da Instrução da Mocidade de Nossa Pátria.

Dissertação de mestrado. Belo Horizonte, UFMG, 2002. Disponível em: http://www. bibliotecadigital.ufmg.br/dspace/bitstream/handle/1843/NSCS-5NGJJF/1000000381. pdf? sequence $=1$. Consultado em 10/6/2015.

ROCHA, Rosa Edite da Silveira. "O Livro no Brasil, uma Perspectiva Histórica das Editoras Brasileiras". São Paulo, Universidade Metodista de São Paulo, 2009. Disponível em: http://www2.metodista.br/unesco/1_Regiocom\%202009/arquivos/trabalhos/ REGIOCOM\%202\%20-\%200\%20Livro\%20no\%20Brasil\%20Uma\%20perspectiva\%20 hist\%C3\%B3rica\%20das\%20editoras\%20brasileiras\%20-\%20Rosa\%20Edite\%20da\%20 Silveira\%20Rocha_ttmp4ac9f888.pdf. Consultado em 6/6/2015.

SACQUIN, Michèle. "Le Livre des Lumières Entre Classicisme et Modernité - L'Apparition de l'Éditeur", in Histoire du Livre. Paris, BnF, s/d. Disponível em: http://classes.bnf.fr/livre/ arret/histoire-du-livre/lumieres/05.htm.

THUAU, Etienne. Raison d'Etat et Pensée Politique à l'Epoque de Richelieu. Paris, Albin Michel, 2000. 